\title{
Território e trabalho: uma inscrição em temporalidades diferentes
}

Christian Azaïs - Membro da Équipe de Recherche sur les Systèmes Industriels (ERSI) de Amiens e do Groupe de Recherche sur l'État, l'Internationalisation des Techniques et le Développement (GREITD); professor da Université de Picardie Jules Verne (UPJV) Pôle Universitaire Cathédrale

\section{Resumo}

O objetivo deste artigo é fornecer uma interpretação possível para a articulação entre trabalho e território, conceitos centrais em economia, em escalas diversas. Para demonstrar essa articulação, recorre-se às ciências sociais e examina-se como os economistas, que sempre raciocinaram com base no espaço, "descobriram" o território, cuja definição não é consensual.. Levanta-se neste texto a hipótese de que a dificuldade de articulação entre o trabalho e o território decorre principalmente de sua inscrição em temporalidades diferentes: num tempo longo e curto no que diz respeito ao território e num tempo curto para o trabalho, o que pode prejudicar o processo de sedimentação dos processos sociais e institucionais.

\section{Abstract}

This paper presents a possible interpretation between work and territory, central concepts in economy, at different levels. In order to demonstrate this articulation, we turn to the social sciences and examine it like the economists, who have always used space as a base, "discovering" the territory in a non-consensual definition.. In this paper, we work with the hypothesis that difficulties between work and territory are mainly caused by their inscription in different temporalities: in a long and short time regarding territory, and in a short term regarding work. This may interfere with the progress of social and institutional sedimentation processes.

\section{Palavras-chave}

Trabalho, território, reestruturação produtiva.

\section{Keywords}

Work, territory, productive reestructing. 


\section{INTRODUÇÃO}

O trabalho e o território são, em escalas diversas, conceitos centrais em economia. O primeiro tem sido objeto de uma literatura florescente; o segundo, descoberto mais recentemente pelos economistas, está em vias de adquirir um lugar de destaque na reflexão. Ora, a articulação desses dois conceitos ainda coloca sérios problemas para os pesquisadores. Com efeito, a maioria das análises não aborda a questão ou, quando o faz, é freqüentemente em detrimento de um ou de outro elemento; raramente os dois são considerados conjuntamente. O objetivo deste artigo é fornecer uma interpretação possível dessa articulação, propondo como grade de leitura sua inscrição diferente no tempo. Esse campo de estudo, presente desde os primórdios da teoria econômica, foi durante vários anos ignorado pelos economistas e, mesmo que alguns tenham mostrado interesse recentemente (LEBORGNE, 1995; RALLET; TORRE, 1995), as dificuldades para chegar a uma definição única do território são testemunhas de obstáculos teóricos. Neste texto proponho indicar algumas pistas de reflexão para que a articulação trabalhoterritório deixe de ser um projeto utópico.

O ponto de entendimento entre os autores que se debruçam sobre a evolução do trabalho e os que se interessam pelo território reside no fato de que fazem dessas duas noções elementos-chave da compreensão da socialização dos indivíduos. A idéia segundo a qual o trabalho é criador de vínculo social encontra-se nos primeiros sociólogos (Durkheim); juristas, politólogos e geógrafos empenham-se para sustentar a idéia segundo a qual o sentimento de pertença a um território é constitutivo do reconhecimento identitário dos indivíduos. Levanto a hipótese de que a dificuldade de articulação entre o trabalho e o território reside principalmente na sua inscrição em temporalidades diferentes, ao mesmo tempo num tempo longo e curto no que diz respeito ao território e num tempo curto para o trabalho, o que pode prejudicar o processo de sedimentação dos processos sociais e institucionais.

Para estudar a articulação possível (plausível?) entre trabalho e território, examinarei sucessivamente a contribuição das ciências sociais e a "descoberta" do território pelos economistas, que até então só raciocinavam em termos de espaço. Isso me levará a tecer considerações sobre o que chamarei os "territórios-atores"; tal noção, na medida em que integra à análise "a pluralidade das temporalidades espacializadas" (BERTHELOT, 1996, p. 68), difere da acepção geográfica do território, para a qual território seria sinônimo de espaço, de região ou de "país". Tal démarche é um convite para pensar o território na sua dupla inscrição 
no longo e no curto prazo, na medida em que permite expressar as temporalidades sociais do trabalho e do território. A multiplicação das tentativas de integração econômica regional para fazer face à concorrência e a procura de soluções locais de desenvolvimento fazem do território um vetor importante da diferenciação dos conjuntos econômicos nacionais e internacionais e, por sua vez, essas mudanças têm um impacto sobre as formas de organização do trabalho. A imbricação no território de sistemas de trabalho não dissociados dos espaços de vida volta, então, a ocupar o centro da análise. Dois exemplos tomados das realidades italiana e brasileira completarão esta reflexão.

\section{1- E POR FALAR EM TERRITÓRIO}

Durante muito tempo o território foi uma categoria analítica dos juristas, politólogos e dos geógrafos; somente recentemente se tornou um conceito usado pelos economistas.

Os juristas, principalmente os constitucionalistas e os publicistas, fizeram dessa noção a pedra de toque das teorias do Estado-nação. Com os conceitos de nação - o "querer viver coletivo" de Renan - e de soberania, o território constitui o alicerce do Estado; é "o modo de existência do Estado no espaço" (ALLIÈS, 1980, p. 12). Em reação a uma concepção imóvel, oposta à consideração de toda relação social, o autor propõe estudar por quais procedimentos e vias que emergem do poder estatal a noção móvel de espaço transforma-se na de território. Será a obra - eis a hipótese que defende - da administração; dito doutra forma, trata-se de superar a idéia segundo a qual o território seria um dado imediato e aistórico do conhecimento e da existência do Estado. O Estado exerce seu poder sobre um território delimitado por fronteiras. Em seu âmbito, expressa-se a conflitualidade das relações sociais, a qual vai imprimir sua marca e dar-lhe uma configuração específica e dinâmica. A importância das instituições é então sugerida. Essas instituições comprovam o ancoramento do território nas relações sociais locais e portanto seu dinamismo. Destaca-se, assim, a inscrição do território no longo prazo. É possível objetar, no entanto, que o autor se interessa tão-somente pelas instituições formais, enquanto, para dar conta da dinâmica territorial, os vínculos informais, as convenções e as regras - que informam também sobre a atividade de trabalho, que também é feita de códigos tácitos e explícitos, de formalidade e de informalidade -, merecem ser examinados; são a expressão de sua maleabilidade e, portanto, de sua capacidade de desempenho no tempo curto. A ciência econômica, nos seus desenvolvimentos recentes, não 
ignorará esses fenômenos.

\section{2 - ESPAÇO E TERRITÓRIO}

Ao interessar-se pela ocupação do espaço, na sua dimensão física e humana, os geógrafos fizeram da relação com o chão a base do exercício da vida em sociedade. A maneira como os indivíduos se apropriam dos fragmentos de espaço e criam uma representação própria está na origem da constituição do território. A análise geográfica evoluiu radicalmente de uma apreensão estática dos fenômenos para uma compreensão dinâmica. A prova encontra-se, para só citar alguns, nos trabalhos de geografia social que sublinham ao mesmo tempo os processos concomitantes de homogeneização e de diferenciação, as contribuições da nova geografia (BENKO; LIPIEZ, 1992), o trabalho sobre a "tectônica do território" (LACOUR, 1993, 1996), que expressa os movimentos que urdem e constituem o alicerce do território ou ainda os estudos de geografia econômica de Krugman (1998), que integra nos seus modelos de análise do espaço os ensinamentos das teorias sobre a concorrência imperfeita.

Durante muito tempo os economistas preferiram a noção de espaço à de território, associando-lhe a de distância, e fazendo desse conceito a base das teorias da localização. Desde 1826, Von Thünen (1831) trata do espaço enquanto fenômeno econômico. A análise de Alfred Weber (1909) da decisão de localização de um produtor individual, que procura minimizar os custos combinados de produção e de entrega de seu produto, indica um único sítio possível de produção. Christaller (1933) sugere que as cidades formam uma hierarquia de lugares centrais e que os maiores podem abrigar um leque mais extenso de atividades. Quanto a Lösch (1940), ele demonstra que um modelo eficiente de lugares centrais levaria a áreas de mercado hexagonais; defende a idéia de que existem atividades econômicas que só podem funcionar num número limitado de lugares (KRUGMAN, 1998, p. 163). Segundo esses teóricos, o espaço é distância e custo e, enquanto custo, há de ser reduzido. Dessa acepção fica excluída toda dimensão social.

De alguns anos para cá, assiste-se a um esforço para ultrapassar a assimilação correntemente feita entre espaço e território e erigir a noção de território em conceito econômico. Pode-se ver aí o efeito da mundialização dos mercados, assim como o reconhecimento da importância das redes na constituição de um sistema produtivo, uma maneira de mostrar interesse metodológico pela dimensão meso. De um ponto de vista teórico, o fato de se levar em conta a temporalidade 
permite distinguir as noções de território e de espaço, não possuindo este último consistência temporal. Se se adota a idéia de que o território é "uma construção histórica [que] encontra seu princípio unificador nas práticas sociais do momento" (PRÉVÔT SCHAPIRA, 1997), ele se distancia nitidamente do espaço. Na literatura econômica, o território ganhou lugar de destaque com os trabalhos sobre os distritos industriais dos socioeconomistas italianos, no fim dos anos 70, ou com os do Grupo de Pesquisa sobre os Meios Inovadores (GREMI), na seqüência dos escritos de Ph. Aydalot. Os primeiros insistem na inscrição temporal dessas formas de desenvolvimento territorial; os segundos sublinham a implicação dessas formas de desenvolvimento nas estruturas institucionais e socioeconômicas de seu "meio", construção que remete indiscutivelmente ao tempo. Desde então, o território aparece sucessivamente como "construção das práticas e das representações dos agentes econômicos" (BELLET, COLLETIS, YUNG, 1993, p. 357) ou como "ator do desenvolvimento econômico" (RALLET; TORRE, 1995, p. 4). Não se reduz tampouco, como afirma com exatidão Veltz (1980, p. 54) ao "desdobramento espacial superposto de organizações de produção". Sua natureza é mais complexa. "É enquanto espaço social concreto de interações, mercantis e não mercantis, que o território, em diversas escalas, intervém na competitividade das firmas e das economias, e não somente como espaço abstrato suporte de regulações normativas ou públicas", escreverá mais tarde esse mesmo autor (VELTZ, 1996, p. 139). O território ocupa um lugar ativo no desenvolvimento, por ser produtor de externalidades, das quais pode (e deve) por efeito retroativo se beneficiar, razão pela qual Veltz o apresenta como "estrutura ativa (de desenvolvimento, ou de estagnação, ou de retrocesso) e não somente como um perímetro-receptáculo das atividades" (VELTZ, 1996, p. 142). Os territórios não são campos de manobra, mas sim atores; têm um papel de "intermediação territorial" (LACOUR, 1996, p. 34), o que afasta qualquer apreciação determinista quanto a sua emergência e a seu desdobramento.

Fruto, entre outras coisas, das "práticas sociais do momento", o território encontrará nas formas de mise au travail um dos elementoschave de sua sedimentação. Portanto, o ponto de convergência entre o território e o trabalho reside na temporalidade, mas numa temporalidade curta que precisa, também, da temporalidade longa do território para expressar-se plenamente. A territorialidade, que é antes de mais nada "relação entre os homens" (RONCAYOLO, 1990, p. 195), permite ao trabalho e às formas variadas que adota tornar-se lugar privilegiado de construção do vínculo social, de comunicação entre os homens, fazendo 
com que o termo "território", diferentemente do termo "espaço", não seja "a mera e simples cópia modernizada do local dos anos 70" (PAILLIART, 1993, p. 150), mas sim o sinal de novas indagações sobre a estruturação social do espaço. Como qualquer processo, tal estruturação está inscrita no tempo, é dinâmica.

Na tentativa de compreender as formas de desenvolvimento territorial, o que tentaram fazer os "distritólogos" ou os defensores da abordagem em termos de "meios inovadores", sustento o argumento segundo o qual o desenvolvimento baseia-se principalmente numa diferenciação dos territórios, mais do que na sua uniformização. Se houver uniformização, ela concerne principalmente à esfera financeira, enquanto as esferas da produção e do trabalho conhecem fenômenos de fragmentação, de estilhaço e de recomposição. Tais tendências têm um impacto sobre o modo de apreensão do desenvolvimento e das formas de integração. Explicam em parte as tentativas dos pesquisadores, os quais, quando tratam dos fenômenos de integração regional ou da questão mais específica do território e dos fluxos que o permeiam, vêem-se obrigados a articular diferentes abordagens para traduzir da maneira mais adequada possível as múltiplas configurações da dinâmica territorial (ABDELMALKI; COURLET, 1996). A dinâmica territorial não se resume às expressões "desenvolvimento de cima para baixo" (top-down) ou "desenvolvimento de baixo para cima" (bottom-up): no primeiro caso, o território seria submetido a uma mundialização esmagadora ou seria somente o produto de agentes institucionais de promoção; no segundo, seria a expressão gloriosa de uma versão localista do desenvolvimento (à la small is beautiful). As influências que caracterizam e estruturam (algumas) os territórios provêm ao mesmo tempo das esferas global e local. O desenvolvimento não é nem exclusivamente exógeno, nem exclusivamente endógeno. Com efeito, entendê-lo na sua dimensão endógena equivaleria a extirpar as determinações de ordem macroeconômica ou macrossocial; captar somente a dimensão exógena, por sua vez, levaria a negar a importância da estruturação socioeconômica e histórica, produto das instituições e dos homens que "fazem" o território e nele trabalham. Tal procedimendo conduziria a esconder a dimensão mesoeconômica ou mesossocial, a apreensão do território ficaria, portanto, escamoteada. Enquanto lugar de afirmação das interdependências societais (GILLY; PECQUEUR, 1995, p. 305), o território fornece ao trabalho o quadro de sua expressão e "de volta" é alimentado ou atropelado por ele. Quanto ao trabalho, lugar privilegiado, também, do enunciado das inter-relações, não posso em absoluto subscrever a crônica de sua morte anunciada (Meda, Rifkin), pois, como afirma Palloix (1998, p. 44), o capital - e sua inscrição territorial, acrescentaria - sairia fragilizado por tal operação. 
Para expressar a dinâmica própria do território, que não é somente um simples receptáculo do qual os agentes econômicos (empresas, principalmente) tiram recursos - ótica tradicional das externalidades e para significar também que as mudanças na esfera do trabalho adquirem certa visibilidade no território e terão uma incidência sobre ele, não é doravante possível concebê-lo como dotação em fatores. O território tem uma lógica própria, que é sua capacidade não somente de produzir, mas também de apoderar-se das externalidades positivas e fazê-las render e, portanto, de ser agente socialmente inovador. Dessa capacidade de inovação resultarão sua especificidade e o êxito das empresas que aí se localizam. O território desempenhará o papel de incitador e de regulador de interesses múltiplos e divergentes, graças às instituições que souber federar. Torna-se ator econômico e político de seu desenvolvimento. Cabe-lhe então fazer frutificar os fluxos que lhe conferem uma dinâmica e que provêm cada vez mais da imbricação entre as esferas do trabalho e as da vida.

\section{3 - TERRITÓRIO DE TRABALHO E TERRITÓRIO DE VIDA}

A imbricação entre trabalho e extra-trabalho é doravante um fato consumado em sociologia do trabalho. Se durante muito tempo essas duas esferas estiveram separadas, foi mais por razões de ordem metodológica (mas também em decorrência de certa visão do mundo) do que em função de uma crença cega de que a fronteira que separa a fábrica do resto de seu ambiente era insuperável. Para ilustrar as interrelações recíprocas entre o território e as formas de mise au travail, escolherei dois exemplos, o da mobilidade dos trabalhadores e o do engajamento dos indivíduos, tomados em universos diferentes, de um distrito industrial italiano (AZAÏS, 1992, 1997; AZAÏS; CORSANI, 1998) e de uma joint-venture nipo-brasileira, sediada na Amazônia. Os dois exemplos, que não têm a priori nenhum ponto comum, participam, contudo, da representação que não vê na evolução do capitalismo contemporâneo uma dicotomia entre o que ocorre na esfera do trabalho e o que acontece no território. A idéia segundo a qual a grande empresa fordista podia "pousar-se" em qualquer território é verdadeira somente em parte, na medida em que não é em absoluto independente das normas de consumo nem das formas de regulação societais. Trabalho e território surgem como dois fenômenos imbricados, já que cabe ao território construir suas vantagens, mostrar-se atraente num mundo concorrencial, fortemente aberto às influências exteriores. 


\section{4 - MOBILIDADE DOS TRABALHADORES E CONSTRUÇÃO DO TERRITÓRIO: UM EXEMPLO ITALIANO}

Como redesenhar o território a partir do trabalho? Corsani (1998), evocando a experiência de Lumezzane $^{1}$ (AZAÏS; CORSANI, 1997), sublinha a importância que teve, nos anos 50, a "emigração" dos camponeses do Sul da Itália na constituição de uma classe de pequenos empresários no Norte industrial. Os que tinham fugido do campo encontravam refúgio no trabalho posté em fábrica ou nos interstícios industriais do norte do país; não hesitavam em submeter-se a pesadas jornadas de trabalho nas fábricas fordistas, alimentando a firme esperança de acumular uma pequena poupança e conseguir a prazo o seu próprio negócio. Quem não trabalhava nos grandes estabelecimentos do triângulo industrial Gênova-Torino-Milão juntava-se ao lote de empregados das pequenas e médias empresas dos distritos industriais. Com o passar dos anos, parte dessa população de origem rural lograva converter-se em pequeno empresário e promover um desenvolvimento extensivo do território por via de um fenômeno de difusão de pequenas e médias indústrias. O crescimento de muitos dos distritos industriais e desse em particular - deu-se com base numa competitividade-custo, para a qual a qualidade não aparecia como uma exigência absoluta. O êxito econômico permitiu o desenvolvimento do território e desempenhou um papel importante na atratividade que exercia ao mesmo tempo sobre as populações vizinhas e de outras regiões da Itália, que percebiam a possibilidade de ter acesso à condição de empresário. O trabalho serviu como cimento identitário, embora as condições materiais de trabalho fossem geralmente muito duras e os salários, pouco elevados. Ele facilitou a mobilidade não somente para uma camada de empresários mais antigos, que chegou a constituir um tipo de burguesia industrial local, mas também para esses recém-chegados, que pouco a pouco vieram a ocupar os postos-chave do poder local, industrial ou não. O sentimento

\footnotetext{
${ }^{1}$ Lumezzane, situado num vale alpino da província de Brescia (Val Trompia), é um distrito industrial especializado na produção de artigos para casa (louça, talheres, panelas etc.), de torneiras e de formas. Sua população ativa e a população industrial ativa mais do que duplicaram entre 1950 e 1970.
} 
de pertença ao território se expressará, no decorrer dos anos 90, no sucesso dos candidatos da Liga e no esquecimento das raízes originais ${ }^{2}$.

Hoje a situação mudou; as condições macroeconômicas e culturais não são mais as mesmas. A concorrência internacional obrigou os produtores locais a integrar uma démarche qualidade no seu processo de produção, e vários foram levados a recorrer a designers de Milão para diferenciar sua produção e exportá-la. A criação de empresas, outrora atividade florescente, regrediu nos últimos anos: nos anos 80, seu número caiu cerca de 15\%, e o dos empregados, $11 \%$. Os empresários já não podem mais contentar-se como no passado em sacar do território externalidades para assegurar seu crescimento, devem participar ativamente da construção de vantagens e da instauração com as instituições locais de estruturas de "governança", que possibilitem ao território imprimir sua especificidade. Os atores do território encontram-se assim na obrigação de coordenar suas ações e de achar os elementos de sua diferenciação, esta não podendo mais repousar numa qualidade medíocre ou numa qualificação baixa da mão-de-obra.

No plano demográfico, o imigrante dos anos 90 já não é mais cidadão italiano, é "extracomunitário" ${ }^{3}$ e suas margens de manobra reduziram-se seriamente. É-lhe proibido imigrar com a família; às vezes mais bem qualificado do que os nativos, não pode pretender instalar-se de maneira duradoura na região como os seus colegas italianos dos anos 50 o fizeram e é submetido às tarefas mais difíceis e aos horários de trabalho mais flexíveis. Se, por acaso, ele consegue acumular qualquer dinheiro, não o inviste in loco mas sim o utiliza para o sustento de sua família que reside fora. De território produtor de integração social, o território passou a território de exclusão, de fragmentação social. A solidariedade tão lisonjeada como qualidade e sinal distintivo dos distritos industriais evaporou-se. Inúmeras empresas deixaram o vale por não encontrar mais aí nem o espaço físico ${ }^{4}$ para exercer sua atividade

\footnotetext{
${ }^{2}$ Com efeito, os antigos "imigrados" das regiões meridionais não manifestam o desejo de voltar ao "país" ao se aposentarem. Seu "país" é Lumezzane. Os mais jovens nasceram aí e não têm razões a priori para deixar o seu lugar de residência. Nas últimas eleições regionais, a Liga do Nord, conhecida pelo seu desejo de autonomia perante o poder central, recolheu mais de $60 \%$ dos votos no município.

${ }^{3}$ Quer dizer, principalmente do Senegal, da Costa do Marfil ou do Gana e do Marrocos ou Paquistão, num grau menor. O número de imigrantes passou de 900, em 1996, para 3000, em 1998, no Val Trompia.

4 Apesar das obras de terraplenagem faraônicas realizadas para que as empresas "nativas" permanecessem no lugar e não emigrassem na planície, perto da auto-estrada Milão-Veneza, como fez um grande número de empresas de Lumezzane. O termo que mais bem resume a arquitetura do sítio de Lumezzane é o de empilhamento (das fábricas, das moradias, no mais das vezes reunidas no mesmo edifício).
} 
industrial, nem as condições requeridas para se posicionar de maneira favorável no mercado, aproximando-se dos eixos de circulação dos homens e das idéias. A prazo, a sobrevivência do sistema produtivo local está ameaçada, pois não há mais transmissão do saber-fazer às jovens gerações, perdendo-se a herança e definhando o território.

A população jovem desse distrito industrial perdeu o entusiasmo com o trabalho dos metais nas fábricas familiares e tende, também, cada vez mais a preferir ao trabalho em fábrica e ao ritmo imposto ${ }^{5}$ um trabalho mais independente, embora mais duro, porém, mais bem remunerado e exercido à margem dos controles fiscais. As mães, por sua vez, desejam para seus filhos uma vida diferente da que seus maridos e elas mesmas chegaram a conhecer: longas jornadas de trabalho $^{6}$ em atividades perigosas e não reconhecidas socialmente, ausência de férias etc. O que aconteceu? Se, nos anos 50, a procura por esse tipo de trabalho em fábricas ou em pequenos estabelecimentos industriais, apesar das más condições de trabalho, podia explicar-se pelo desejo secreto dos indivíduos de se instalar por conta própria e portanto de ter acesso à condição cobiçada e possível ainda de empresário, nos anos 90, tendo mudado o contexto econômico e sociopolítico, tal perspectiva não chega mais a nutrir o imaginário dos jovens. As bases sobre as quais se construiu o sistema produtivo local estão abaladas de tal maneira que sua permanência fica incerta. Sem poder mais limitar sua competitividade a uma competitividade-custo, repousando numa mão-de-obra não qualificada e barata, o território deve reestruturar-se e fazer da qualidade de seus produtos e da qualificação de seus trabalhadores uma diretriz básica. Sua sobrevivência depende disso. Com efeito, o grau de qualificação é localmente muito baixo, a formação dos trabalhadores é uma preocupação marginal para os empregadores. Atualmente, as pouco mais de 1000 empresas não contam mais do que 20 engenheiros. No entanto, as probabilidades de mobilidade social são maiores para os mais qualificados, exceto

\footnotetext{
${ }^{5}$ Estas reflexões baseiam-se em uma pesquisa realizada em Lumezzane, que revelou que os jovens empregados rejeitam maciçamente o trabalho nas fábricas, preferindo um trabalho autônomo, não declarado, com jornadas de trabalho mais extensas, certo, mas com salários 3 ou 4 vezes superiores e a possibilidade de ter um tempo livre maior ou pelo menos de poder organizá-lo à vontade (por exemplo, reservar períodos longos de férias no ano para poder viajar). Dos 900 empregados (trabalhadores sem qualificação) na fábrica da Iveco (FIAT), em 1992, 5 anos depois, 800 haviam deixado o trabalho na fábrica e trabalhavam por conta própria em atividades não registradas.

${ }^{6}$ As jornadas de trabalho são raramente inferiores a 10 ou até a 11 horas, e as semanas de trabalho incluem freqüentemente o sábado e o domingo.
} 
para os "extracomunitários"7 . Esse fenômeno assinala uma mudança na natureza do trabalho e mais ainda na sua percepção. Com efeito, e isso é facilmente compreensível, os trabalhadores menos qualificados têm um desejo maior de se "virar" de outra maneira do que no trabalho assalariado, o que os leva a procurar situações alternativas, como indicou o exemplo dos jovens trabalhadores. Não se trata meramente do reflexo de uma evolução passageira, mas de uma mudança nas mentalidades que pode prefigurar transformações radicais no sistema produtivo. O território deve adaptar-se às condições movediças do sistema de emprego local e propor, por intermédio de suas instâncias reguladoras, soluções de troca para perdurar.

Por um lado, esse exemplo ilustra o fato de que o modelo canônico do trabalho fordista não se constitui mais numa regra, nem tampouco atrai as novas gerações. É, portanto, a condição teórica do assalariamento que é questionado, na medida em que perde seu "efeito cumulativo" (BIDET, 1995, p. 246) e deixa de ser percebido como centro a partir do qual se organizam e se agenciam as socialidades diversas, que um dia foram até constitutivas do território. Essas socialidades evoluem rapidamente e com elas o trabalho, o território precisa de continuidade, precisa poder prever as mudanças para se adaptar, senão a brecha entre os dois tende a cavar-se de maneira irreversível, não oferecendo mais o território as condições de atratividade para as empresas, nem para a população trabalhadora. Nos anos 90 , as autoridades locais construíram instituições de apoio e de promoção do território, seguindo o exemplo de outros distritos industriais na Itália. O ex-banco local aliou-se, por exemplo, a um banco de um município vizinho e trocou de nome ${ }^{8}$; colocou à frente de sua direção o ex-prefeito de Lumezzane, que, por sua vez, é fabricante local. Outrossim, o município está revitalizando a Lumetel, uma agência de promoção das atividades industriais locais, criada nos anos 80, que tem por vocação assessorar as empresas e, entre outras atividades, montou um extenso banco de dados sobre o sistema produtivo local.

Por outro lado, esse caso destaca a imbricação entre o território e o trabalho. Ambos experimentam uma evolução inscrita na interdependência; ou seja, o que afeta um afeta necessariamente o outro,

\footnotetext{
7 Constatou-se, em vários casos, que os trabalhadores mais qualificados eram os "extracomunitários".

${ }^{8}$ Com efeito, o ex-Banco di Lumezzane juntou-se ao Banco di Palazzolo para formar o Banco di Brescia, operação importante, simbolicamente.
} 
ainda que num tempo diferente. Pelo fato do território - entendido como fruto de uma proximidade geográfica, institucional e organizacional ao mesmo tempo (RERU, 1993) - mostrar-se inovador socialmente, nos anos 50, ele atrai para si um fluxo de jovens trabalhadores oriundos do campo do Sul da Itália, as condições macroeconômicas o permitiam. Ocorre, então, um movimento de criação de empresas, que atuará como um chamado para novos aprendizes-empresários. Não sendo insuperáveis as barreiras ao ingresso, o território facilita a mobilidade dos trabalhadores e a emergência de novas formas de trabalho que, por sua vez, o dinamizam e lhe asseguram as condições de sua reprodução.

Embora os empresários locais se queixem atualmente da escassez de mão-de-obra e tenham de recorrer à mão-de-obra imigrada, a nova força de trabalho admitida já não é mais considerada como portadora de um projeto socioeconômico e político, não lhe sendo outorgadas as condições necessárias para tal. Por conseguinte, o território não aparece mais, apesar dos esforços redobrados das autoridades locais, como podendo alimentar um sentimento de pertença e um engajamento irrestrito por parte dos que o "fazem" ou dos que deveriam "fazê-lo", ou seja, de quem trabalha nele. O trabalho não é mais o único portador de identidade coletiva. Não se pode mais considerá-lo como ator e motor para o território; assim, o deslocamento que se produziu para a esfera política indica uma mudança na natureza do sentimento identitário. O trabalho assalariado perdeu seu papel de recomposição social. A mobilidade pelo trabalho já não mobiliza mais, cabe aos atores locais "enriquecê-lo", com o intuito de sacudir a bandeira do território e fazêlo viver.

Em razão de sua incapacidade de inovar em matéria de organização do trabalho (qualificação da mão-de-obra, adoção de formas mais modernas de administração do pessoal, implicação dos trabalhadores etc.), é grande para o sistema produtivo local o perigo que corre o território-ator de se tornar território de subcontratação e, portanto, de a longo prazo não mais controlar o seu desenvolvimento. A riqueza do território depende, também, da do trabalho dos homens que fazem o território. Nesse sentido, território de vida e território de trabalho estão interligados.

No entanto, é preciso fazer umas ressalvas. Não é porque algumas grandes empresas emigraram nos últimos anos e foram procurar fora do espaço estritamente geográfico externalidades que Lumezzane não lhes oferecia mais, que Lumezzane está fadado a desaparecer enquanto território. Talvez seja mais um sinal de que o território está se dilatando, 
não mais restrito a seu recinto geográfico, mas repetindo, integrando as dimensões institucional e organizacional. A presença a distância ${ }^{9}$ de empresas "de" Lumezzane pode contrinuir para reforçar a identidade local. Fica, sem embargo, difícil avaliar a extensão e os limites da rede que está em constituição. A partir de quando é possível considerar que uma empresa saiu da esfera de influência do território? Tal indagação levanta a questão da defesa dos interesses do lugar. O caso do Banco ilustra, por meio da mudança de razão social, a ampliação da esfera de atuação do território para além do simples espaço geográfico.

O segundo exemplo ilustra o fato de que a adoção de uma técnica de organização de trabalho julgada inovadora não significa obrigatoriamente o êxito compartilhado pelos indivíduos ao mesmo tempo no seu território de trabalho e no seu território de vida.

\section{5 - IMPLICAÇÃO DOS TRABALHADORES E CONSTRUÇÃO DO TERRITÓRIO: UM EXEMPLO BRASILEIRO ${ }^{10}$}

O segundo caso ilustra em que medida a adoção de uma técnica nova de organização do trabalho numa fábrica de alumínio situada na Amazônia brasileira teve um impacto direto sobre o meio em que está inserida a fábrica - trata-se da implementação no seio dessa unidade de um programa de Qualidade Total. Deixarei os exemplos falar por si sós sobre as transformações aparentes e subjacentes que conheceu o território e sua influência sobre as formas de mise au travail. Os exemplos esclarecem ao mesmo tempo as recomposições territoriais em curso e seu impacto sobre os indivíduos e a organização do trabalho.

\subsection{UM DUPLO MOVIMENTO: UNIFORMIZAÇÃO NO TRABALHO E DIFERENCIAÇÃO NO TERRITÓRIO}

A implantação da unidade industrial em questão abalou

\footnotetext{
${ }^{9}$ Distantes geograficamente, mas presentes pelos laços mantidos com a comunidade de Lumezzane.

${ }^{10}$ Estas reflexões são o resultado do trabalho de campo efetuado no âmbito da pesquisa "Sistemas Produtivos, Território e Transformação das Relações Sociais: Pesquisa comparativa entre complexos industriais e impactos sobre o meio ambiente no Brasil e na França", realizada conjuntamente com professores da Université de Picardie e da Universidade Federal do Pará e, principalmente, com a professora Edna Castro (1996), coordenadora do NAEA, no Convênio CAPES/COFECUB 171/95. Para uma descrição detalhada do complexo industrial, criado em 1985, vide estudos realizados por professores do Núcleo de Altos Estudos Amazônicos/ UFPA e dissertações de mestrado de seus orientandos.
} 
evidentemente o habitat natural das populações nativas, mas aí não reside o propósito de meu estudo. Várias evidências indicam que as transformações sofridas pelo território têm levado ao mesmo tempo a uma uniformização das relações de trabalho no interior da fábrica e a uma diferenciação fora dela, no espaço geográfico. Esses dois movimentos participam da mesma dinâmica: responsabilizar o trabalhador para que exerça um autocontrole sobre o lugar de trabalho e sobre seu lugar na vida. Esses movimentos fazem parte da linha da superação das formas fordistas de organização do trabalho, tornada necessária pela concorrência nacional e internacional.

\subsection{A UNIFORMIZAÇÃO DAS RELAÇÕES DE TRABALHO NA FÁBRICA}

Alguns exemplos, aparentemente anódinos, ilustram a uniformização - ou a homogeneização - das relações de trabalho. A semelhança dos uniformes, qualquer que seja a posição hierárquica do indivíduo, a supressão das salas de restaurante diferenciadas, uma para a gerência e outra para os operários, embora a operação não tenha sido muito fácil, servem para disfarçar as diferenças de sexo e de estatuto entre os empregados. Todos assim podem compartilhar a mesma meta.

No restaurante, todos comem juntos e a mesma coisa, embora as "afinidades hierárquicas" juntem-se na mesma mesa ou no mesmo canto. Não há privilegiados, e todos devem participar da campanha do "zero resto". Um cartaz lembra que "30 milhões de brasileiros têm fome", outro parabeniza a todos por terem atingido os objetivos.

A valorização do trabalhador está presente, também, na linguagem adotada. Assim, o uso do termo "cliente" para designar os indivíduos que trabalham em setores diferentes da empresa tem um duplo papel: o de satisfazer as necessidades do trabalhador (numa perspectiva de mercado das relações internas à empresa) - portanto, apresenta um efeito valorizador individualmente -, mas também o de prepará-lo psicologicamente para uma saída (forçada ou voluntária) da empresa ou, no melhor dos casos, para sua externalização. De qualquer forma, o trabalhador sente-se valorizado e reconhecido socialmente: embora não tenha poder efetivo em seu setor, tem a ilusão de se considerar e ser percebido como dono (... de si).

No entanto, a padronização produzida graças ao respeito esperado dos procedimentos operacionais ${ }^{11}$ pode levar ao resultado inverso do

11 Trata-se do nome dado à descrição por escrito de cada operação relativa a um posto. Sua redação cabe ao titular do cargo 
esperado. Eles garantem a continuidade do processo de produção, se o trabalhador faltar. Outrossim, provocam no trabalhador que os colocouno papel um sentimento de valorização. Por fim, é o reconhecimento oficial de que é ele mesmo quem faz esta ou aquela operação, por mínima que seja; com isso, ele acaba obtendo algum reconhecimento dos seus pares, coisa que antes não ocorria. Paralelamente, no entanto, o trabalhador é vítima de uma perda de individuação, a relação personalizada e afetiva que ele mantinha com "sua" máquina ou com a tarefa a realizar definhou. Com efeito, defender a implicação do trabalhador numa produção em que o seu imaginário, seu desejo de potência, sua subjetividade são menos solicitados do que em processos de produção com os quais ele se identificava pode ser contraproducente a longo prazo para a empresa. A revelação de seus conhecimentos tácitos corre o risco de não ser vista com bons olhos pelo trabalhador sobre quem pesa como uma espada de Dâmocles a ameaça de uma demissão, já que está ciente de que essas práticas de gestão da força de trabalho assemelham-se a formas de flexibilização do trabalho.

O trabalhador que outrora tinha poder - sobre a tarefa a executar ou sobre a máquina, que ele havia "domado" ou que dela se tinha apropriado, dando-lhe um apelido, por exemplo - encontra-se agora despossuído. Portanto, a uniformização procurada pode ter o efeito inverso do que se esperava, ou seja, o de não ser mais criadora de riqueza para a empresa, nem eventualmente promotora de bem-estar para o trabalhador.

O exemplo escolhido, o da adoção do Total Quality Control (TQC), sutilmente traduzido pelos operários pela expressão "Tem-que-ser", ilustra o fato de que não são totalmente obnubilados pela autonomia conquistada. O objetivo procurado pela direção pode desembocar no resultado oposto e provocar o aparecimento de formas de lutas. De fato, a empresa já falhou na tentativa de implementação de um programa de Qualidade Total (QT). Imputou-se a culpa do fracasso aos gerentes que, conscientes de que iam perder seu poder, não acataram os critérios do programa. Alguns foram demitidos, outros deixaram a empresa. Somente alguns anos depois, em razão da necessidade das certificações ISO 9000 e 14 000, nova tentativa foi feita, cuidando-se dessa vez de evitar qualquer nova rejeição. Para tal, a direção escolheu uma mulher nova, engenheira, e encarregou-a de introduzir os parâmetros da QT nos diversos setores da fábrica. A escolha dessa pessoa não foi à toa. Por ter ocupado vários cargos na produção, ela conhece muito bem, embora seja jovem, o meio masculino e, em razão de sua juventude e de sua feminilidade, seus colegas 
homens não a percebem como uma ameaça, sendo-lhe assim relativamente mais fácil transmitir "sua" mensagem.

A disciplina é admitida, introjetada pelos empregados independentemente de seu nível hierárquico. Produz-se, então, uma horizontalização das relações sociais no lugar da fábrica, já que todos são convidados a dar seu palpite para a melhoria do ambiente e do processo de trabalho. A ausência de conflito, pelo menos aparente, é a imagem que prevalece na e da empresa. De fato, nenhuma greve jamais explodiu. À uniformização interna corresponde uma diferenciação que encontra simultaneamente no território seu lugar de expressão.

\section{6 - A DIFERENCIAÇÃO FORA DA FÁBRICA}

Contudo, a homogeneização tem seus limites, e a diferença entre os indivíduos desloca-se do espaço fabril para o exterior, no território ${ }^{12}$. O território que circunda a fábrica é fortemente estratificado socialmente. De um lado, as aldeias que já existiam antes da chegada da fábrica ou as que se criaram do nada registraram um aumento de sua população devido à presença dos trabalhadores que esperam um dia serem empregados. A essa população, agregou-se a dos que foram demitidos após a fase de construção, a dos empregados das subcontratadas e a dos comerciantes que conseguem obter indiretamente alguns frutos da riqueza distribuída pela fábrica. Por outro lado, a Vila dos Cabanos, lugar de moradias pertencentes à CVRD, se comparada com o resto do território, parece ser um lugar privilegiado. Fora da fábrica, à primeira vista, o espaço da "aldeia" - Vila dos Cabanos - é também um território aberto. Quem quiser pode entrar sem ter de identificar-se ${ }^{13}$. É inegável que morar na Vila dos Cabanos é um privilégio, em relação às condições de vida nas aldeias vizinhas. O aluguel das casas pago à CVRD, que administra a Vila, é derisório, mas está vinculado evidentemente ao fato de permanecer na empresa. O espaço da Vila é amplo, arejado, arborizado, porém é estruturado socialmente como uma "pequena Brasília". Com efeito, as casas são aparentemente todas iguais ou quase, são abertas e deixam ver seu interior. Ora, todavia, tal casa é "a do

\footnotetext{
${ }^{12}$ O território é composto pela fábrica, pela Vila dos Cabanos, zona residencial construída pela empresa, que surge como lugar privilegiado pelas condições de higiene de vida (espaço cuidado, limpo), e pelas antigas aldeias que cresceram de forma desordenada com a industrialização da região e que abrigam muitas favelas e umas moradias precárias.

${ }^{13} \mathrm{O}$ que não é o caso de todos os conjuntos habitacionais da CVRD, como, por exemplo, o de Carajás. A Vila dos Cabanos foi construída pela CVRD.
} 
engenheiro fulano", tal outra é "a do gerente", outra a de um operário.... Dito de outra forma, o espaço da moradia é fruto de uma hierarquização que atravessou as paredes da fábrica, já que não é de bom-tom que se expresse livremente nela. A diferenciação acaba se imiscuindo onde a priori não era esperada. Os dois clubes de lazer, embora abertos a todos, não recebem naturalmente todos. Do mais chique, alguns se excluem, seja por razões financeiras ou de posição social, seja ainda por não terem vontade de passar o seu fim de semana sob o olhar do seu gerente, preferindo guardar um resquício de autonomia.

A Vila tampouco é o espaço idílico que se poderia imaginar, embora o cenário seja sem dúvida mais acolhedor do que o dos arredores. Problemas de droga têm surgido entre os jovens, típicos de uma população que deseja fugir de um ambiente sem saída ${ }^{14}$. É verdade que o horizonte fica algo limitado para eles; seguir o caminho traçado pelos seus pais pode não ser forçosamente o mais atraente. Quando a empresa instalou-se na região, contratou vários funcionários qualificados oriundos de regiões do Sul do país, onde havia uma tradição de trabalho nas fábricas de alumínio. Assim, os primeiros técnicos foram recrutados no Centro-Sul, em Minas Gerais principalmente. É mais do que concebível que seus filhos queiram agora traçar o seu próprio destino e, eventualmente, estudar nas escolas e universidades de Minas Gerais ou São Paulo, onde se formaram seus pais e onde eles têm raízes familiares. A pressão social e moral é forte; ela faz desse lugar, apresentado como símbolo de modernidade, un espantalho para indivíduos que não desejam que os princípios em vigor dentro da fábrica infiltrem-se na sua vida privada. A confusão vida privada-vida pública, própria das novas formas de trabalho e de engajamento dos trabalhadores, participa da construção do território.

De fato, tudo leva a que se tenha uma representação aparentemente diferenciada do território, como se o território do trabalho (ou seja, o da fábrica) devesse ser radicalmente diferente do território de vida dos trabalhadores, quando os dois estão profundamente imbricados e surgem em temporalidades sociais quase idênticas.

\section{7 - TERRITÓRIO DE VIDA VERSUS TERRITÓRIO DE TRABALHO: RUMO A UMA NOVA ARTICULAÇÃO?}

\footnotetext{
${ }^{14}$ Ir a Belém, a cidade grande vizinha, distante uns $40 \mathrm{~km}$, é difícil. Na maior parte do tempo, a estrada é impraticável e, além disso, representa um desvio que duplica a distância; para apanhar o barco, é preciso ir até o porto, que fica longe, e a demora entre um e outro barco é grande. A única saída possível é ter parentes em Belém que garantam o alojamento, o que é o caso de uma pequena parte da população da Vila.
} 
Se, no início da descoberta das "virtudes" da produção flexível, caracterizada pelos fluxos tensos, pela subcontratação e pelo trabalho autônomo, economistas e sociólogos do trabalho destacavam o fato de estarmos perante um novo paradigma de produção, batizado "pósfordismo" ou "especialização flexível", parece hoje em dia cada vez mais difícil esconder o seu caráter totalizante. Com efeito, toda tentativa de "luta de dentro" parece vã. Ou seja, já não se trata mais, como bem dizia Taylor, de reduzir a porosidade do trabalho, ou de lutar contra os gastos, quaisquer que sejam, o que supunha um mínimo de autonomia trabalhadora. Hoje em dia a margem de manobra é reduzida; ou você está "dentro e a favor" (MARAZZI, 1996, p. 50) ou, então, você é excluído. O controle lembra, guardadas as devidas proporções, aquele que existia no capitalismo social (fábricas com vila operária), com o agravante de que é mais disfarçado, mais sorrateiro, pelo ganho efetivo (porém ilusório) de responsabilização e de autonomia permitido ao trabalhador.

Vigoravam relações paternalistas no capitalismo social, que poderiam em último caso transformar-se, no caso de sanções do patrão, em relacionamento conflituoso. O "bom patrão" tornava-se, então, o "patrão ruim", causa da perda de todas as benesses vinculadas ao emprego: trabalho (para o trabalhador e sua família), casa, educação para os filhos, consideração etc. Agora, como as relações são individualizadas, cabe ao próprio trabalhador a responsabilidade pelo bom andamento da empresa. Assim, ele acaba tendo plena consciência do ganho em responsabilidade e autonomia conseguido (e que não se pode negar), mas, se por acaso, por problemas de redução de custos, ele for demitido, o responsável pela demissão não será a fábrica, mas ele mesmo, que não soube adaptar-se às novas normas da empresa - as quais são evidentemente normas de "qualidade". Ele se auto-excluirá.

Outrossim, como sua subjetividade participa da criação de riquezas, as conseqüências para sua saúde mental, no caso de demissão, serão mais violentas, já que o fato de não ter conseguido valorizar o objetivo da empresa, que deve ser o dele também, passa a ser vivido como um fracasso pessoal. Evidentemente, tal processo coloca o trabalhador pósfordista numa posição de inferioridade em relação ao trabalhador taylorista, com menores possibilidades de lutar. A divisão concepção/ execução permitia-lhe não se sentir responsável pela não consecução de um objetivo. Não tinha autonomia, portanto, não tinha nada a perder. Executava a sua tarefa e pronto. No entanto, no pós-fordismo, o trabalhador, que deve ser polivalente, sente-se atingido na sua intimidade. 
Se considerarmos agora a separação trabalho/extra-trabalho, típica de uma relação taylorista de trabalho (AZAÏS, 1993), tal separação tende a diluir-se no pós-fordismo. Assim, já que as normas da (e na) empresa são consideradas como ótimas, o trabalhador é levado a transportar aquilo que se faz dentro da empresa para fora, para a sua moradia. O espaço de valorização encontra-se tanto na fábrica quanto no seu exterior. O processo é o mesmo. A "qualidade" invade seu território de vida. Não se assiste mais, como prevalecia no taylorismo ou no fordismo, a uma nítida separação (pelo menos pretendida) entre o trabalho e o extra-trabalho, mas essas duas esferas aparecem como estreitamente imbricadas, como testemunha a declaração de uma empregada, que dizia ter de "fazer o Seiri"15 em sua bolsa. Ela se vangloriava de ter conseguido levar os princípios vigentes na fábrica para dentro do seu espaço doméstico, com êxito. Assim, a auto-exploração fica mascarada pela participação nos objetivos da empresa. Produção e reprodução passam então a contribuir para o processo de valorização do capital.

O controle que outrora se exercia no modelo paternalista no âmago da fábrica e no espaço de reprodução do trabalhador e de sua família é hoje um controle mais insidioso. É o próprio trabalhador quem se responsabiliza pelo sucesso na passagem da fronteira de dentro para fora da fábrica. Ele acabou internalizando o controle que antes, no capitalismo social, lhe fora imposto pelo patrão e, no taylorismo e no fordismo, pela máquina. Agora só depende dele. É ele quem espontaneamente assume com os membros de sua família os princípios que lhe são transmitidos na fábrica e que ele mesmo adota por se tratar do "melhor" modelo. A responsabilidade, então, é individualizada; não é mais unicamente da alçada do patrão da fábrica ou da gerência como antes. Ou seja, a personalidade do trabalhador está em jogo, e a distinção entre modos de trabalho e modos de vida fica tênue. Requer-se o seu engajamento. Passou-se da disciplina ao autocontrole.

A autonomia dá aos trabalhadores a sensação de serem donos de seu destino e de terem uma função dentro da empresa, que é deles, e que devem incorporar. A polivalência, por sua vez, indica que individualmente os trabalhadores são reconhecidos, o que é prejudicial para o coletivo. A autonomia e a polivalência desempenham o papel de reforço da subjetividade, com o intuito de quebrar a resistência interna dos trabalhadores, embora eles implementem técnicas suscetíveis de

${ }^{15}$ Termo japonês que significa "ordem, higiene, senso da arrumação". Trata-se de um dos $5 S$. 
levar à extinção de seu cargo na empresa.

Contudo, reconhecer a autonomia do trabalhador, alimentar sua polivalência pode levá-lo um dia a ultrapassar as barreiras e a exigir que essa autonomia seja cada vez mais verdadeira e não somente "atéonde-a-gerência-deixar".

\section{8 - UMA SÉRIE DE PARADOXOS}

Com a instauração de programas de qualidade, assiste-se a um paradoxo, caracterizado, por um lado, por um certo esgotamento do taylorismo e do fordismo e, por outro lado, pelo mesmo motivo, por uma agudização do controle que outrora era vigente no taylorismo. Assim, em razão do acirramento da concorrência e do esgotamento progressivo dos ganhos de produtividade, das mudanças na organização do trabalho - que se traduzem pela procura de uma maior flexibilidade do trabalho e de uma maximização da eficiência produtiva dentro da empresa -, a demanda por maior qualidade e diferenciação dos produtos torna-se mais aguçada (LALLEMENT, 1994, p. 48). Paradoxalmente, esse mesmo movimento que torna imprescindível a busca da qualidade reforça os elementos constitutivos do taylorismo, de tal forma que se tem hoje o direito de afirmar que o movimento em defesa da qualidade exacerba as formas tayloristas de gestão da mão-de-obra e reaviva até formas paternalistas consideradas como ultrapassadas.

Se é óbvio que o teor do controle inerente ao taylorismo modificouse - por não mais vir unicamente da hierarquia da empresa ou dos fornecedores (a montante), mas vir também dos "clientes" (a jusante) -, assiste-se, todavia, a uma recomposição do poder da hierarquia, de forma sorrateira, em razão da exigência de conformidade às normas. A diferença básica em relação ao modelo anterior reside no fato de que o antigo princípio taylorista "concepção/execução" foi substituído por um princípio de "responsabilização/polivalência", dentro da margem de autonomia deixada pela submissão aos limites impostos pela empresa, quando não é pela concorrência. Encontrou-se nela um inimigo intocável. Assim, o conflito mudou de parceiros: não se trata mais de um conflito "patrão/empregado", contra o novo inimigo ficam óbvios os limites de cada um.

Contudo, a lógica centralizadora que prevalece no novo modelo reforça em última instância a separação das tarefas oriundas do taylorismo pelo engajamento individual nos objetivos da gerência geral da empresa. A redução dos níveis hierárquicos e a descentralização das responsabilidades operacionais não são em absoluto incompatíveis com 
uma centralização acirrada das responsabilidades estratégicas (no nível dos gerentes) e com uma normalização das relações de trabalho, dos processos técnicos e da circulação das informações entre as unidades da fábrica.

Portanto, pode-se afirmar que a polivalência, cujo objetivo, quando foi implementada nas fábricas, nos anos 60, era combater o absenteísmo, pela possibilidade dada às gerências de intercambiar os trabalhadores, não questiona fundamentalmente a divisão vertical do trabalho; é somente uma maneira diferente de exercê-la: permanecem a codificação e a definição das tarefas. Assim, a autonomia tão anunciada não beneficia os trabalhadores.

A démarche qualidade pretende, por sua vez, substituir a linguagem monolítica, a única linguagem, a da direção (encarregada da concepção), por uma linguagem que leve em conta a diversidade dos indivíduos. Por quê? Porque a primeira é pobre para enfrentar as conseqüências da reestruturação produtiva e a busca de competitividade. As transformações em curso não se localizam unicamente no âmbito das empresas, mas possuem uma amplidão macroeconômica e social cujo impacto no território ainda precisa ser avaliado em detalhes. No território estão os elementos de uma nova modalidade de mise au travail.

O discurso sobre a qualidade é ao mesmo tempo um discurso da diversidade, mas o objetivo é produzir novamente um discurso único, no qual se tenha a impressão de que os indivíduos/operários foram integrados ou, melhor dizendo, se integraram, embora fossem parcialmente recuperados. Se tal sistema permite à empresa permanecer competitiva e conseguir ganhos de produtividade, ele não deixa de ter repercussões nas relações de trabalho internas à fábrica e no seu exterior imediato, no que diz respeito não somente às empresas subcontratadas, mas também aos trabalhadores, à esfera do extra-trabalho, da reprodução, à esfera doméstica. Assim, as regras do jogo da organização do trabalho evoluem para uma responsabilização dos trabalhadores. Simultaneamente, a participação e a polivalência são exigidas deles, em troca de margens ilusórias de autonomia. O objetivo é fazer com que se diluam as diferenças e unir sob a mesma bandeira o conjunto dos indivíduos que compõem a empresa, numa versão que difere radicalmente da versão clássica da "cultura de empresa", pelo seu apelo à subjetividade.

Estamos, portanto, diante de uma ideologia que nega qualquer autonomia intelectual em relação aos objetivos da empresa, que não permite mais individualizar a fronteira entre o trabalho e o não trabalho 
(MARAZZI, 1996, p. 52), entre a fábrica e o seu território, no qual ela cava suas raízes e sua sobrevivência ${ }^{16}$.

\section{CONCLUSÃO}

A análise da articulação entre o trabalho e o território impõe-se em razão da busca de competitividade das empresas e de atratividade dos territórios. Para se entender a dinâmica territorial, o exame das formas múltiplas e movediças de mise au travail informa sobre os fluxos que atravessam e fazem o território. A abordagem em termos de dinâmica territorial destaca a inscrição dos indivíduos, das organizações e das instituições em temporalidades sociais diversas, cujo efeito combinatório não é dado uma vez por todas. O trabalho possibilita ao território expressar sua concretude, e inversamente o território reforça a inscrição temporal do trabalho. O tempo, por sua vez, entendido na sua dimensão histórica, permite captar o sentido global de fenômenos que apareceriam como dissociados. Ele confere à noção de território uma "espessura" que o diferencia do espaço.

O território e o trabalho relacionam-se com temporalidades diferentes. Com efeito, o primeiro inscreve-se simultaneamente num tempo longo e num tempo curto, enquanto o segundo, na sua versão moderna, se se acata a acepção de Bidet de "procura de um resultado no menor tempo" ou segundo a qual "a lógica do trabalho é a da economia do tempo" (BIDET, 1995, p. 245), remete a um tempo curto. O que caracteriza o trabalho para um indivíduo é o fato de não se inscrever na continuidade, seja porque é precário - e a atualidade é infelizmente rica demais -, seja porque, tendo-se em vista a multiplicidade das formas de mise au travail, não se encontra um modo único de relação salarial, já que as trajetórias de trabalho dos indivíduos não obedecem a um percurso previamente traçado e imutável. As situações de trabalho nos países subdesenvolvidos ensinam que a descontinuidade na vida profissional de um indivíduo entre períodos de inatividade ou de emprego nas atividades formais e informais é fato corriqueiro, o que estão aprendendo os países desenvolvidos.

O processo de fixação dos trabalhadores em seus territórios de trabalho e de vida passou por várias etapas (AZAÏS ; CORSANI, 1998, p. 54-55). Por exemplo, fica nítido o vínculo estreito entre o território de vida do trabalhador e o seu território de trabalho na manufatura com

\footnotetext{
${ }^{16}$ Em razão, entre outras, da rede de subcontratantes de que depende e que dependem dela.
} 
vila operária; esse laço não era muito mais tênue no taylorismo ou no fordismo, já que cabia ao Estado-providência operacionalizar da melhor forma possível o funcionamento do sistema produtivo e promover uma forma de relação salarial.

O exame do caso italiano revela que as condições de reprodução do sistema local têm mudado radicalmente desde os anos 50, e com elas as modalidades de mise au travail. Isso prova que é preciso levar em conta as mudanças no sistema de trabalho local, por terem um impacto sobre a permanência do território no tempo. Ou o sistema produtivo local se adapta às mudanças societais em curso e, melhor, as antecede, ou, então, corre o risco, a longo prazo, de se decompor. Nesse caso, o território não será mais ator de seu desenvolvimento, gozando de certa autonomia e capaz de delinear seu percurso.

O caso brasileiro indica, por sua vez, que a interdependência entre o mundo do trabalho e o território não se limita exclusivamente aos territórios compostos de pequenas unidades de produção, mas concerne também aos sistemas produtivos que abrigam uma grande indústria. Essa interdependência revela também o impacto que podem ter novas modalidades de organização do trabalho sobre um território. O apelo à subjetividade dos indivíduos, enquanto elemento de valorização do capital e ruptura definitiva da dicotomia trabalho/extra-trabalho, leva a não mais considerar a relação salarial canônica como a forma predominante, o que os países subdesenvolvidos entenderam há muito tempo. Não se trata de um pseudofim do trabalho, mas simplesmente de um questionamento sobre a natureza das mudanças na esfera do trabalho e o papel do território, este último atuando como lugar de emergência possível de uma dinâmica econômica, social e até mesmo política.

O vínculo entre o trabalho e o território reside então no questionamento da irreversibilidade dos fenômenos; convém, portanto, perguntar-se em que medida o território domina ou não sua inscrição no tempo. Duas vias são possíveis: uma consiste em empreender estudos detalhados sobre a mobilidade geográfica e social dos indivíduos; outra consistiria em estudar as relações de subcontratação para se examinar a natureza dos laços que unem grandes e pequenas empresas e suas margens de autonomia. Recorrer a um tempo longo, a séries históricas suficientemente amplas permitiria, então, detectar os pontos de ruptura ou simples transformações do trabalho no território. Seria um meio para combinar abordagens do tempo que originalmente não pareciam compatíveis e para perfazer o estudo da dinâmica territorial. 


\section{REFERÊNCIAS}

ABDELMALKI, Lahsen; COURLET, Claude. Les nouvelles logiques du développement. Paris: L'Harmattan, 1996.

ALLIÈS, Paul. L'invention du territoire. Grenoble: PUG, 1980.

AZAÏS, Christian. Sistemas produtivos locais franceses e distritos industriais italianos: elementos de uma problemática na intersecção da Sociologia e da Economia. Estado e Sociedade, Brasília, v. VII, n. 1/2, p. 34-62, jan./ dez. 1992. Version française: Systèmes productifs locaux français et districts industriels italiens: éléments d'une problématique à l'intersection de la sociologie et de l'économie. Université de Picardie Jules Verne, 1992. Document ronéo.

AZAÏS, Christian. L'industrie grippée dans la ville qui tourne: tradition et modernité au Brésil. Revue Canadienne d'Études du Développement, [S.l.], v. XIV, n. 2, p. 197-223, 1993.

AZAÏS, Christian. Dynamique territoriale, localisation et systèmes productifs locaux: quelques repères théoriques. In: PALLOIX, Christian; RIZOPOULOS, Yorgos. Firmes et économie industrielle. Paris: L'Harmattan, 1997. p. 255-277.

AZAÏS, Christian; CORSANI, Antonella. Systèmes industriels locaux et réseaux d'innovation. Pôle SHS, Conseil Régional de Picardie, Amiens, Compiègne, mai et oct. 1997. Rapports de recherche. Document ronéo.

AZAÏS, Christian; CORSANI, Antonella . Travail, territoire, post-fordisme. Espaces et Sociétés, Paris, L'Harmattan, n. 92/93, p. 43-66, 1998. Numéro spécial L'inscription territoriale du travail, coordonné par B. Pecqueur.

BELLET, Michel; COLLETIS, Gabriel; YUNG, Yannick. Introduction au numéro spécial Économie de Proximités. RERU, [S.1.], n. 3, 1993.

BENKO, Georges; LIPIETZ, Alain. Les régions qui gagnent, districts et réseaux: les nouveaux paradigmes de la géographie économique. Paris: PUF, 1992.

BERTHELOT, Jean-Michel. Sciences sociales, temps et espace. In: OSTROWETSKY, S. (Ed.). Sociologues en ville. Paris: L'Harmattan, 1996. p. 65-70.

BIDET, Jacques. Le travail fait époque. In: BIDET, J.; TEXIER, J. La crise du travail. Paris: PUF, Actuel Marx, 1995. p. 245-259. 
CASTRO, Edna. Racionalidade e novos padrões na gestão do trabalho em grandes empresas na Amazônia. In: MAGALHÃES, S., BRITO, R. CASTRO, E. Energia na Amazônia. Belém, UFPA/MPEG/UNAMAZ, 1996.

CHRISTALLER, W. Les centres de l'Allemagne du sud. Local: Editora, 1993.

CORSANI, Antonella. Métamorphoses du rapport salarial et dynamiques territoriales: le cas des districts industriels en Italie. Revue Innovations, [S.1.], n. 8, p. 61-84, 1998.

GILLY, Jean-Pierre; PECQUEUR, Bernard. La dimension locale de la régulation. In: BOYER, R.; SAILLARD Y. Théorie de la régulation: l'état des savoirs. Paris: La Découverte, 1995. p. 304-312 (Col. Recherches).

KRUGMAN, Paul. Space: the final frontier. Journal of Economic Perspectives, [S.1.], v. 12, n. 2, p. 161-174, 1998.

LACOUR, Claude. La tectonique des territoires: entre éclatement et intégration. In: DUPUY, C.; GILLY, J.-P. (Ed.). Industrie et territoires en France. Paris: La Documentation Française, 1993.

LACOUR, Claude. La tectonique des territoires: d'une métaphore à une théorisation. In: PECQUEUR, B. (Ed.). Dynamiques territoriales et mutations économiques. Paris: L'Harmattan, 1996. p. 25-48.

LALLEMENT, Michel (Ed.). Travail et emploi: le temps des métamorphoses. Paris: L'Harmattan, 1994 (Col. Logiques Sociales).

LEBORGNE, M. Travail et territoire. In: BIDET, J.; TEXIER, J. (Org.). La crise du travail. Paris: PUF, Actuel Marx Confrontation, 1995. p. 71-80.

LÔBO, Marco Aurélio Arbage. Estado e capital transnacional na Amazônia: o caso da Albrás-Alunorte. Belém: UFPA/NAEA, 1996.

LÖSCH, A. L'économie de la localisation. Local: Editora, 1940.

MARAZZI, Christian. Le langage comme moyen de la production marchande. Futur Antérieur, [S.1.], n. 35-36, p. 49-70, 1996.

PAILLIART, Isabelle. Les territoires de la communication. Grenoble: PUG, 1993.

PALLOIX, Christian. Salarisation restreinte et marchés du travail. Cahiers de l'Économie de l'Innovation, [S.1.], n. 7-1, p. 41-59, 1998. 
PRÉVÔT SCHAPIRA, Marie-France. Territoires, pouvoirs et sociétés en Amérique latine. Tours: Université de Tours François Rabelais, UFR de Droit, d'Economie et des Sciences Sociales, 1997. Rapport d'habilitation à diriger des recherches, document ronéo.

RALLET, Alain; TORRE, André (Coord.). Économie industrielle et économie spatiale. Paris: Economica, 1995.

RERU, Paris, n. 3, 1993. Numéro spécial Économie de proximités.

RONCAYOLO, M. La ville et ses territoires. Paris: Gallimard, 1990 (Col. Folio Essais).

VELTZ, Pierre. Nouveaux modèles d'organisation. In: BENKO G. (Ed.). La dynamique spatiale de l'économie contemporaine. Paris: Éditions de l'Espace Européen, 1980.

VELTZ, Pierre. Mondialisation, villes et territoires: l'économie d'archipel. Paris: PUF, 1996.

VON THÜNEN, Johann Heinrich. L'État isolé. Paris: Guillaumin, 1851 Tradução francesa do original publicado em 1826.

WEBER, Alfred. La théorie de la localisation des industries. Local: Editora, 1909. 